\title{
EFIKASI HERBISIDA GLIFOSAT TERHADAP GULMA DI LAHAN TANAMAN KELAPA SAWIT (Elaeis guineensis Jacq.) BELUM MENGHASILKAN
}

\author{
Laeli Mukarromah, Dad R. J. Sembodo \& Sugiatno \\ Jurusan Agroteknologi, Fakultas Pertanian Universitas Lampung \\ Jl. Prof. Dr. Soemantri Brodjonegoro no. 1 Bandar Lampung 35145 \\ Email: mukarromah_laely@yahoo.com
}

\begin{abstract}
ABSTRAK
Keberadaan gulma pada areal tanaman kelapa sawit belum menghasilkan (TBM) mengakibatkan terjadinya kompetisi antara gulma dengan tanaman kelapa sawit. Pengendalian gulma menggunakan herbisida lebih menguntungkan daripada dengan cara pengendalian gulma yang lain. Penelitian bertujuan untuk mengetahui dosis herbisida glifosat yang efektif untuk mengendalikan bobot kering gulma total dan gulma pergolongan pada pertanaman kelapa sawit, perubahan komposisi jenis gulma pada piringan tanaman kelapa sawit belum menghasilkan setelah aplikasi herbisida glifosat, dan daya racun herbisida glifosat pada tanaman kelapa sawit belum menghasilkan. Penelitian dilakukan di perkebunan kelapa sawit belum menghasilkan milik petani di Desa Muara Putih, Kecamatan Natar, Kabupaten Lampung Selatan dan di Laboratorium Gulma, Fakultas Pertanian, Universitas Lampung, Bandar Lampung dari bulan November 2011 sampai dengan Januari 2012. Perlakuan yang diuji adalah herbisida berbahan aktif isopropylamina glifosat dengan dosis 1080, 1440, 1800, dan $2160 \mathrm{~g}^{-1}$, penyiangan mekanis, dan tanpa perlakuan (kontrol). Rancangan percobaan yang digunakan adalah rancangan kelompok teracak sempurna (RKTS) dengan 4 ulangan. Data hasil pengamatan dianalisis ragam dan perbedaan nilai tengah perlakuan diuji dengan Uji Beda Nyata Terkecil (BNT) pada taraf 5\%. Hasil penelitian menunjukkan bahwa herbisida glifsat dosis $1080-2160 \mathrm{~g}^{-1}$ menekan pertumbuhan gulma total di lahan kelapa sawit TBM pada 4, 8 dan 12 MSA; Herbisida glifosat dosis 1080-2160 $\mathrm{g} \mathrm{ha}^{-1}$ menekan pertumbuhan gulma daun lebar di lahan kelapa sawit TBM pada 4 dan 8 MSA, gulma rumput ditekan pada 12 MSA, dan gulma teki ditekan pada 4 MSA; Terdapat perubahan komposisi jenis gulma akibat aplikasi herbisida glifosat yang ditunjukkan oleh jumlah jenis gulma yang berbeda pada setiap perlakuan yang dibandingkan dengan kontrol; dan semua taraf dosis herbisida glifosat yang diuji tidak meracuni tanaman kelapa sawit belum menghasilkan.
\end{abstract}

Kata Kunci: Herbisida glifosat, gulma, kelapa sawit.

\section{PENDAHULUAN}

Tanaman kelapa sawit (Elaeis guineensis Jacq.) mempunyai nilai ekonomi yang penting bagi kehidupan manusia untuk memenuhi kebutuhan akan minyak nabati (Syamsulbahri, 1996). Salah satu faktor yang harus diperhatikan dalam meningkatkan laju pertumbuhan tanaman kelapa sawit belum menghasilkan adalah faktor lingkungan di sekitar tanaman, terutama masalah keberadaan gulma. Keberadaan gulma di areal kelapa sawit TBM dapat mengakibatkan terjadinya kompetisi antara gulma dengan tanaman dalam memperoleh unsur hara, air, sinar matahari, dan ruang tumbuh (Tim Penulis Penebar Swadaya, 1994).

Pengendalian gulma di perkebunan dapat dilakukan dengan cara mekanis, kultur teknis, hayati, dan kimiawi (Sukman dan Yakup, 1995). Untuk keberhasilan pengendalian gulma dapat dilakukan dengan menggunakan kombinasi keempat cara tersebut. Pengendalian gulma pada areal tanaman kelapa sawit belum menghasilkan pada umumnya dilakukan secara kimiawi menggunakan herbisida (Satyawibawa dan Widyastuti, 1999). Gulma yang tumbuh di areal tanaman kelapa sawit TBM umumnya sangat beragam jenisnya. Menurut Satyawibawa dan Widyastuti (1999), keberadaan gulma di lahan perkebunan kelapa sawit dapat menghambat pertumbuhan dan menurunkan produksi sekitar $15-20 \%$. Selain itu gulma dapat mengganggu kegiatan pengelolaan tanaman seperti pemupukan, pengendalian hama dan penyakit.

Salah satu herbisida yang sering digunakan pada piringan kelapa sawit TBM adalah herbisida berbahan aktif glifosat. Herbisida glifosat adalah herbisida yang memiliki spektrum pengendalian luas yang bersifat tidak selektif. Efektivitas pemberian herbisida ditentukan oleh dosisnya. Dosis herbisida yang tepat akan dapat 
mematikan gulma sasaran, tetapi jika dosisnya terlalu tinggi akan merusak tanaman budidaya (Nurjannah, 2003). Penelitian bertujuan untuk mengetahui dosis herbisida glifosat yang efektif untuk mengendalikan bobot kering gulma total dan gulma pergolongan pada piringan tanaman kelapa sawit belum menghasilkan, perubahan komposisi jenis gulma pada piringan tanaman kelapa sawit belum menghasilkan setelah aplikasi herbisida glifosat, dan daya racun herbisida glifosat pada tanaman kelapa sawit belum menghasilkan.

\section{BAHAN DAN METODE}

Penelitian dilakukan di perkebunan kelapa sawit belum menghasilkan milik petani di Desa Muara Putih, Kecamatan Natar, Kabupaten Lampung Selatan dan di Laboratorium Gulma, Fakultas Pertanian, Universitas Lampung, Bandar Lampung dari bulan November 2011 sampai dengan Januari 2012.Tanaman kelapa sawit belum menghasilkan yang digunakan berumur 4 tahun dan herbisida berbahan aktif isopropil amina glifosat.

Perlakuan diterapkan dalam rancangan perlakuan tunggal dengan enam perlakuan yaitu herbisida glifosat dengan dosis 1080, 1440, 1800, dan $2160 \mathrm{~g} \mathrm{ha}^{-1}$, penyiangan mekanis, dan tanpa perlakuan (kontrol) yang diulang sebanyak 4 kali. Perlakuan diterapkan pada petak percobaan dengan rancangan kelompok teracak sempurna (RKTS). Data hasil pengamatan dianalisis ragam dan perbedaan nilai tengah perlakuan diuji dengan Uji Beda Nyata Terkecil (BNT) pada taraf 5\%.

Areal yang diaplikasi adalah perkebunan kelapa sawit TBM dengan kondisi penutupan gulma pada piringan lebih dari $75 \%$. Jarak tanam kelapa sawit adalah
$9 \times 9 \times 9 \mathrm{~m}$ (sistem segi tiga sama sisi). Setiap satuan percobaan terdiri atas 3 tanaman kelapa sawit dengan diameter perpiringan adalah $3 \mathrm{~m}$. Aplikasi herbisida dilakukan pagi hari, dengan dosis herbisida pada masingmasing perlakuan adalah $(5,6,8$, dan $9 \mathrm{ml}$ per 3 tanaman) dan penyiangan mekanis dilakukan pada 0,4 , dan 8 MSA dengan menggunakan cangkul (Sembodo, 2012). Pengambilan contoh gulma dilakukan pada saat aplikasi 4, 8, dan 12 minggu setelah aplikasi (MSA). Contoh gulma diambil dengan menggunakan kuadran berukuran $0,5 \mathrm{~m} \times 0,5 \mathrm{~m}$ pada tiga titik pengambilan berbeda yaitu 4, 8, dan 12 MSA.Letak petak kuadran ditetapkan secara sistematis. Gulma yang berada di dalam petak kuadran dipotong tepat pada permukaan tanah. Selanjutnya, gulma dikelompokkan berdasarkan jenisnya dan dikeringkan dengan menggunakan oven pada suhu $80^{\circ} \mathrm{C}$ selama $2 \times 24$ jam (bobot sampel konstan), kemudian ditimbang. Peubah pengamatan meliputi bobot kering gulma total, bobot kering gulma rumput, daun lebar, teki, dan tingkat keracunan tanaman kelapa sawit (fitotoksisitas). Pengamatan dilakukan pada 4, 8, dan 12 MSA.

\section{HASIL DAN PEMBAHASAN}

Tabel 1 menunjukkan bahwa pada pengamatan 4 dan 8 MSA, perlakuan dosis herbisida glifosat yang diuji belum dapat menekan pertumbuhan gulma golongan rumput di areal tanaman kelapa sawit TBM. Pengamatan 12 MSA perlakuan dosis herbisida glifosat yang diuji mampu menekan pertumbuhan gulma golongan rumput di areal tanaman kelapa sawit TBM. Menurut Adnan et al.(2012), glifosat merupakan

Tabel 1. Pengaruh perlakuan herbisida glifosat terhadap bobot kering gulma rumput 4, 8, dan 12 MSA.

\begin{tabular}{|c|c|c|c|c|c|c|}
\hline \multirow{3}{*}{ Perlakuan } & \multicolumn{6}{|c|}{ Bobot kering gulma rumput $\left(\mathrm{g} / 0,75 \mathrm{~m}^{2}\right)$} \\
\hline & \multicolumn{2}{|c|}{$4 \mathrm{MSA}$} & \multicolumn{2}{|c|}{$8 \mathrm{MSA}$} & \multicolumn{2}{|c|}{$12 \mathrm{MSA}$} \\
\hline & Asli & $\begin{array}{c}\text { Trans } \\
\sqrt{ }(x+0,5)\end{array}$ & Asli & $\begin{array}{c}\text { Trans } \\
\sqrt{ }(x+0,5)\end{array}$ & As li & $\begin{array}{c}\text { Trans } \\
\sqrt{(x+0,5)}\end{array}$ \\
\hline \multicolumn{7}{|c|}{ Dosis Glifosat $(\mathrm{g} / \mathrm{ha})$ : } \\
\hline 1080 & 0,25 & $0,84 \mathrm{a}$ & 0,55 & $0,97 \mathrm{ab}$ & 0,15 & $0,79 \mathrm{~b}$ \\
\hline 1440 & 0,05 & $0,74 \mathrm{a}$ & 0,00 & $0,71 \mathrm{~b}$ & 1,20 & $1,20 \mathrm{~b}$ \\
\hline 1800 & 0,03 & 0,72 a & 0,45 & $0,94 \mathrm{ab}$ & 0,63 & $1,03 \mathrm{~b}$ \\
\hline 2160 & 0,00 & $0,71 \mathrm{a}$ & 0,3 & $0,88 \mathrm{ab}$ & 0,58 & $1,00 \mathrm{~b}$ \\
\hline Siang Mekanis & 0,03 & 0,72 a & 0,2 & $0,82 \mathrm{ab}$ & 1,40 & $1,30 \mathrm{~b}$ \\
\hline Kontrol & 2,90 & 1,40 a & 3,05 & $1,50 \mathrm{a}$ & 13,60 & $3,22 \mathrm{a}$ \\
\hline BNT $5 \%$ & & 0,84 & & 0,79 & & 0,14 \\
\hline
\end{tabular}

Keterangan : Nilai Tengah yang diikuti oleh huruf yang sama tidak berbeda menurut uji BNT pada taraf uji 5\%. 
herbisida sistemik yang bekerja sangat lambat sehingga kematian gulma sampai akar memerlukan waktu 30 hari.

Tabel 2 menunjukkan bahwa perlakuan dosis herbisida glifosat yang diuji menekan pertumbuhan gulma daun lebar di areal tanaman kelapa sawit TBM pada pengamatan 4 dan 8 MSA. Peningkatan dosis herbisida glifosat yang diuji tidak berpengaruh terhadap daya tekan gulma daun lebar di areal tanaman kelapa sawit TBM pada 4 dan 8 MSA. Pengamatan 12 MSA perlakuan dosis herbisida glifosat yang diuji tidak mampu menekan pertumbuhan gulma daun lebar di areal tanaman kelapa sawit TBM. Tabel 3 menunjukkan herbisida glifosat yang di uji menekan bobot gulma teki pada 4 MSA. Pada 8 dan 12 MSA perlakuan glifosat dosis $1080 \mathrm{~g} / \mathrm{ha}$ pada tidak berbeda nyata dengan kontrol, karena banyak gulma teki yang tumbuh baru. Hasil yang sama ditunjukkan pada penelitian Mawardi (2005), menyatakan bahwa gulma yang teracuni herbisida telah mati pada $2 \mathrm{MSA}$, dan menyebabkan munculnya gulma lain tumbuh baru, baik gulma yang sama maupun gulma lain pada 5 MSA.

Pengamatan komposisi jenis gulma 4 MSA jenis gulma yang tumbuh diidentifikasi berjumlah 13 jenis (Tabel 4). Pengamatan 8 MSA jumlah gulma yang tumbuh diidentifikasi bertambah menjadi 18 jenis, dengan penambahan jenis gulma baru tumbuh yaitu gulma Lindernia ciliate, Melastoma affine, Croton hirtus, Axonopuscompressus, Brachiaria paspaloides. 12

Tabel 2.Pengaruh perlakuan herbisida glifosat terhadap bobot kering gulma daun lebar 4, 8, dan 12 MSA.

\begin{tabular}{ccccccc}
\hline \multirow{2}{*}{ Perlakuan } & \multicolumn{6}{c}{ B obot kering gulma daun lebar $\left(\mathrm{g} / 0,75 \mathrm{~m}^{2}\right)$} \\
\cline { 2 - 7 } & \multicolumn{3}{c}{4 MSA } & \multicolumn{2}{c}{$12 \mathrm{MSA}$} \\
\cline { 2 - 7 } & Asli & $\begin{array}{c}\text { Trans } \\
\sqrt{ }(\mathrm{x}+0,5)\end{array}$ & Asli & $\begin{array}{c}\text { Trans } \\
\sqrt{ }(\mathrm{x}+0,5)\end{array}$ & Asli & $\begin{array}{c}\text { Trans } \\
\sqrt{ }(\mathrm{x}+0,5)\end{array}$ \\
\hline Dosis Glifosat $(\mathrm{g} / \mathrm{ha}):$ & & & & & \\
1080 & 0,95 & $1,20 \mathrm{~b}$ & 4,68 & $2,25 \mathrm{~b}$ & 8,20 & $2,80 \mathrm{~b}$ \\
1440 & 0,93 & $1,17 \mathrm{~b}$ & 5,53 & $2,42 \mathrm{~b}$ & 10,45 & $3,23 \mathrm{ab}$ \\
1800 & 0,40 & $0,92 \mathrm{~b}$ & 3,65 & $2,04 \mathrm{~b}$ & 9,75 & $3,16 \mathrm{ab}$ \\
2160 & 0,08 & $0,76 \mathrm{~b}$ & 5,48 & $2,38 \mathrm{~b}$ & 9,78 & $3,05 \mathrm{ab}$ \\
Siang Mekanis & 0,15 & $0,80 \mathrm{~b}$ & 5,43 & $2,42 \mathrm{~b}$ & 17,45 & $4,19 \mathrm{a}$ \\
Kontrol & 9,05 & $3,03 \mathrm{a}$ & 18,78 & $4,36 \mathrm{a}$ & 17,50 & $4,21 \mathrm{a}$ \\
\hline BNT 5\% & \multicolumn{7}{c}{0,64} & 1,29 \\
\hline
\end{tabular}

Keterangan : Nilai Tengah yang diikuti oleh huruf yang sama tidak berbeda menurut uji BNT pada taraf uji $5 \%$.

Tabel 3. Pengaruh perlakuan herbisida glifosat terhadap bobot kering gulma teki 4, 8, dan 12 MSA

\begin{tabular}{|c|c|c|c|c|c|c|}
\hline \multirow{3}{*}{ Perlakuan } & \multicolumn{6}{|c|}{ Bobot kering gulma teki $\left(\mathrm{g} / 0,75 \mathrm{~m}^{2}\right)$} \\
\hline & \multicolumn{2}{|c|}{$4 \mathrm{MSA}$} & \multicolumn{2}{|c|}{$8 \mathrm{MSA}$} & \multicolumn{2}{|c|}{$12 \mathrm{MSA}$} \\
\hline & Asli & $\begin{array}{c}\text { Trans } \\
\sqrt{ }(x+0,5)\end{array}$ & Asli & $\begin{array}{c}\text { Trans } \\
\sqrt{ }(x+0,5)\end{array}$ & As li & $\begin{array}{c}\text { Trans } \\
\sqrt{ }(x+0,5)\end{array}$ \\
\hline \multicolumn{7}{|l|}{ Dosis Glifosat $(\mathrm{g} / \mathrm{ha})$ : } \\
\hline 1080 & 0,28 & $0,86 \mathrm{~b}$ & 1,40 & $1,30 \mathrm{ab}$ & 11,75 & 3,33 a \\
\hline 1440 & 0,38 & $0,90 \mathrm{~b}$ & 0,70 & $1,07 \mathrm{~b}$ & 1,10 & $1,17 \mathrm{~b}$ \\
\hline 1800 & 0,40 & $0,92 \mathrm{~b}$ & 0,80 & $1,11 \mathrm{~b}$ & 1,82 & $1,48 \mathrm{~b}$ \\
\hline 2160 & 0,30 & $0,88 \mathrm{~b}$ & 0,55 & $1,00 \mathrm{~b}$ & 1,15 & $1,24 \mathrm{~b}$ \\
\hline Siang Mekanis & 0,03 & $0,72 \mathrm{~b}$ & 1,93 & $1,47 \mathrm{~b}$ & 2,00 & $1,49 \mathrm{~b}$ \\
\hline Kontrol & 8,98 & $2,87 \mathrm{a}$ & 4,85 & $2,12 \mathrm{ab}$ & 4,97 & $1,96 \mathrm{ab}$ \\
\hline $\mathrm{BNT} 5 \%$ & & 0,76 & & 0,88 & & 1,39 \\
\hline
\end{tabular}

Keterangan : Nilai Tengah yang diikuti oleh huruf yang sama tidak berbeda menurut uji BNT pada taraf uji 5\%. 
Tabel 4. Nilai Summed Dominance Ratio (SDR) gulma pada 4, 8 dan 12 MSA.

\begin{tabular}{|c|c|c|c|c|c|c|c|c|c|c|c|c|c|c|c|c|c|c|}
\hline \multirow{3}{*}{ 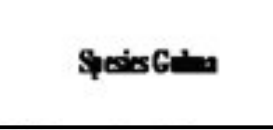 } & \multicolumn{18}{|c|}{ SOR } \\
\hline & \multicolumn{6}{|c|}{ 4MSA } & \multicolumn{5}{|c|}{8 MSA } & \multicolumn{7}{|c|}{ 12MBA } \\
\hline & P1 & $\mathbf{P 2}$ & $\mathbf{P 3}$ & $\mathbf{P 4}$ & $\mathbf{P}$ & $\overline{\mathbf{F}}$ & P1 & $\overline{\mathbf{P}}$ & $\overline{P 3}$ & $\overline{\mathbf{P 4}}$ & $\overline{\mathbf{P}}$ & $\mathbf{P} \mathbf{F}$ & PI & $\overline{\mathbf{P 2}}$ & $\mathbf{P B}$ & $\overline{\mathbf{P 4}}$ & P5 & $\mathbf{P} \mathbf{6}$ \\
\hline Galngen han Har & & & & & & & & & & & & & & & & & & \\
\hline 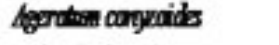 & $17(2)$ & $15(4)$ & & 13(3) & $42(1)$ & $18(2)$ & $2(1)$ & $2(2)$ & $17(2)$ & $n(1)$ & $17(2) 1$ & 19(I) & $13(2)$ & 29 (l) & $17(2)$ & $37(1)$ & $2(1)$ & $17(2)$ \\
\hline Pádwerdin brasienss & $6(7)$ & $21(2)$ & $10(4)$ & & $15(2)$ & 12(3) & $20(2)$ & 20 & 31 (l) & $12(3)$ & $19(1) 1$ & 13(3) & $10(9)$ & $17(2)$ & $21(1)$ & $11(2)$ & $13(2)$ & $8(3)$ \\
\hline Ippeseatriblen & $15(3)$ & $18(3)$ & $23(3)$ & $17(2)$ & & $11(4)$ & $12(4)$ & $4(6)$ & $15(3)$ & $7(9)$ & $3(9)$ & $9(4)$ & $11(4)$ & $6(6)$ & & $3(8)$ & $3($ ) & $8(3)$ \\
\hline Obminelina difisa & $10(3)$ & $10(5)$ & 33(l) & & $15(2)$ & 6(9) & $4(7)$ & $14(3)$ & & $13(2)$ & $13(4)$ & $8(9)$ & $13(3)$ & & $6(5)$ & $3(2)$ & & $7(4)$ \\
\hline Livigna alion & & & & & & & $3(0)$ & $7(4)$ & $9(4)$ & $12(3)$ & $5(7)$ & & $2(0)$ & $7(5)$ & $15(3)$ & $10(3)$ & $4(6)$ & $4(0)$ \\
\hline Epportiaprijifin & $10(9)$ & $8(6)$ & & & & & $5(6)$ & & & & $6(6)$ & $5(7)$ & & & & & & $2(t)$ \\
\hline Bpptis cquitite & & & & & & & & & & & & & & 12(3) & $6(5)$ & & $9(4)$ & $6(5)$ \\
\hline Outonhirtes & & & & & & & & $6(5)$ & & & $4(\pi)$ & $16(2)$ & & & & & & \\
\hline 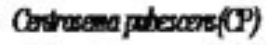 & & & & & & 2(n) & $4(7)$ & $3(7)$ & & & & & & & $3(7)$ & & 2(n) & $4(6)$ \\
\hline Cidzainhint & $9(6)$ & & & & & $3(7)$ & & & & & & $3(n)$ & & & & & $3(7)$ & \\
\hline Plyilathes riverie & & & & & & & & & & & & & 2(t) & $3(7)$ & $3(7)$ & $5(7)$ & 2(n) & $2($ (1) \\
\hline Clevere ntichoperma & & & & & & $2($ () & & & & & & & & $3(7)$ & $5(6)$ & & 2(n) & $2($ (t) \\
\hline Itictoma offire & & & & & & & & & & $5(6)$ & & $3(t)$ & & & & & & \\
\hline Briggron simmerasis & & & & & & & & & & & & & & & & & & $2($ (t) \\
\hline Gabegen nept & & & & & & & & & & & & & & & & & & \\
\hline Digibriatenuta & & $6(7)$ & $8(9)$ & & $15(2)$ & & $3(\theta)$ & & $4(6)$ & & & & 2(t) & $9(4)$ & $8(4)$ & $8(5)$ & $8(5)$ & $24(1)$ \\
\hline Lranpes arepress & & & & & & & & & 6(5) & $4(7)$ & $5(7)$ & & & & & & $11(3)$ & $4(6)$ \\
\hline Onockn dextilan & 13(4) & & & & & 6(5) & & & & $4(7)$ & & & & & & & & \\
\hline 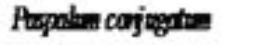 & & & & & & $5(6)$ & $5(6)$ & & & $4(7)$ & & & & & & & & \\
\hline Prechinia papadoids & & & & & & & & & & & & $7(6)$ & & & & & & \\
\hline Galngentdi & & & & & & & & & & & $5(7)$ & & & & & & & \\
\hline Cpens powilus & 19(1) & $2(1)$ & $26(2)$ & $57(1)$ & & $6(9)$ & $9(9)$ & & & $8(4)$ & $15(3)$ & $2(9)$ & $9(0)$ & $3(1)$ & $3(1)$ & $3(\mathrm{~B})$ & $8(3)$ & \\
\hline Opers campreses & & & & $13(3)$ & $15(2)$ & $29(1)$ & 13(3) & $14(3)$ & $17(2)$ & $5(6)$ & $7(9) 1$ & 13(3) & 33(l) & & $5(6)$ & $9(4)$ & 2(r) & $8(3)$ \\
\hline Opens hitingen & & & & & & & & & & & & $2(9)$ & $5(7)$ & $7(5)$ & $8(4)$ & $6(6)$ & $3(1)$ & $3(0)$ \\
\hline TOTAL & 100 & 100 & 100 & 100 & 100 & 100 & 100 & 100 & 100 & 100 & 100 & 100 & 100 & 100 & 100 & 100 & 100 & 100 \\
\hline
\end{tabular}

MSA jumlah gulma yang tumbuh mengalami pengurangan menjadi 17 jenis, dengan jenis gulma yang berkurang adalah Paspalum conjugatum, Cynodon dactylon, Bracaria paspaloides, Melastoma affine, Croton hirtus. Sedangkan gulma yang tumbuh baru pada 12 MSA adalah Digitariaternata, Erigeron sumatrensis, dan Hyptiscapitata. Menurut Sukman dan Yakup (1995), bukan tanaman dan gulma yang terjadi kompetisi dan dapat menurunkan hasil pertanian tetapi antar gulma dapat berkompetisi dalam perebutan unsur hara.

Perubahan komunitas dapat ditentukan bila nilai $\mathrm{C}<75 \%$. Semakin kecil nilai $\mathrm{C}$, semakin banyak terjadi perubahan komposisi jenis gulma pada perlakuan yang dibandingkan, yaitu perlakuan gulma dikendalikan dengan glifosat dibandingkan dengan perlakuan kontrol. Pengamatan 4 dan 8 MSA nilai $C$ terkecil pada dosis $1800 \mathrm{~g} \mathrm{ha}^{-1}$ yaitu $33 \%$ dan $52 \%$. Hal ini menunjukkan bahwa terjadi perubahan komunitas gulma terbanyak pada petak perlakuan glifosat dosis $1800 \mathrm{~g} \mathrm{ha}^{-1}$ dibandingkan dengan perlakuan lain (glifosat 1080, 1440, $2160 \mathrm{~g} \mathrm{ha}^{-1}$, dan penyiangan mekanis). Sedangkan pada 12 MSA, terjadi perubahan komunitas gulma terbesar pada perlakuan glifosat dosis $1080 \mathrm{~g} \mathrm{ha}^{-1}$ dengan nilai C 57\%. Apriadi et al. (2013), menyatakan terjadinya perubahan komunitas gulma menunjukkan adanya perubahan pada komunitas gulma dari kondisi tanpa pengendalian. Adanya perbedaan tanggapan jenis gulma terhadap herbisida yang diaplikasikan dan kecepatan tumbuh gulma dapat menjadi penyebab terjadinya perubahan komunitas gulma. Sehingga memungkinkan tumbuhnya spesies gulma yang sebelumnya tertekan.

Berdasarkan data bobot kering gulma total, persentase keracunan dan bobot kering gulma pergolongan terlihat bahwa herbisida glifosat mampu menekan pertumbuhan gulma. Pengamatan persentase keracunan gulma total secara visual dengan melihat dan menduga persentase keracunan gulma total ternyata memiliki data yang sejalan dengan data bobot kering gulma total dan bobot kering gulma dominan yang 
dihitung dengan menimbang semua gulma yang diambil dari petak contoh yang berbeda, mencakup gulma yang terlihat secara visual dan gulma yang tertutupi. Data tersebut dapat dilihat pada Tabel 5 dan 6 , data persentase keracunan yang tinggi sejalan dengan data bobot kering yang semakin rendah. Hal ini menunjukan bahwa herbisida glifosat mampu mengendalikan gulma. Menurut Nurjannah (2003), herbisida glifosat yang telah ditranslokasikan keseluruh bagian gulma terutama pada bagian akar yang dapat menyebabkan kematian gulma secara lebih efektif. Selain itu, herbisida glifosat mampu bertahan lama di dalam tanah dan tetap aktif sehingga mampu menekan pertumbuhan gulma lebih lama (Hermawan et al., 1995).
Berdasarkan pengamatan fitotoksisitas herbisida glifosat tidak menunjukan gejala keracunan pada tanaman kelapa sawit belum menghasilkan, glifosat hanya meracuni gulma yang berada pada piringan tanaman kelapa sawit. Hasil ini dapat menjadi rekomendasi bagi para petani karena herbisida glifosat aman diaplikasikan pada piringan tanaman kelapa sawit belum menghasilkan.

\section{KESIMPULAN}

Dari penelitian ini dapat disimpulkan bahwa Herbisida glifosat dosis 1080-2160 $\mathrm{g} \mathrm{ha}^{-1}$ menekan pertumbuhan gulma total di lahan kelapa sawit TBM

Tabel 5. Pengaruh herbisida glifosat terhadap bobot kering gulma total pada 4, 8, dan 12 MSA.

\begin{tabular}{ccccc}
\hline \multirow{2}{*}{ Perlakuan } & \multicolumn{4}{c}{ Bobot kering gulma total $\left(\mathrm{g} / 0,75 \mathrm{~m}^{2}\right)$} \\
\cline { 2 - 5 } & Asli & Trans $\sqrt{ }(\mathrm{x}+0,5)$ & Asli & Asli \\
\cline { 2 - 5 } & 1,48 & $1,38 \mathrm{~b}$ & $6,63 \mathrm{~b}$ & $10,08 \mathrm{c}$ \\
\hline Dosis Glifosat $(\mathrm{g} / \mathrm{ha})$ : & 1,35 & $1,34 \mathrm{~b}$ & $6,23 \mathrm{~b}$ & $12,75 \mathrm{c}$ \\
1080 & 1,68 & $1,33 \mathrm{~b}$ & $4,90 \mathrm{~b}$ & $12,20 \mathrm{c}$ \\
1440 & 0,38 & $0,91 \mathrm{~b}$ & $6,43 \mathrm{~b}$ & $11,50 \mathrm{c}$ \\
1800 & 0,20 & $0,83 \mathrm{~b}$ & $8,03 \mathrm{~b}$ & $24,43 \mathrm{~b}$ \\
2160 & 20,93 & $4,56 \mathrm{a}$ & $26,50 \mathrm{a}$ & $38,03 \mathrm{a}$ \\
\hline Siang Mekanis & \multicolumn{5}{c}{0,66} & 3,32 & 10,49 \\
Kontrol & &
\end{tabular}

Keterangan : Nilai Tengah yang diikuti oleh huruf yang sama tidak berbeda menurut uji BNT pada taraf uji 5\%.

Tabel 6. Pengaruh perlakuan herbisida glifosat terhadap tingkat keracunan gulma total 4, 8, dan 12 MSA.

\begin{tabular}{|c|c|c|c|c|c|c|}
\hline \multirow{3}{*}{ Perlakuan } & \multicolumn{6}{|c|}{ Tingkat Keracunan Gulma Total (\%) } \\
\hline & \multicolumn{2}{|c|}{ 4MS A } & \multicolumn{2}{|c|}{$8 \mathrm{MSA}$} & \multicolumn{2}{|c|}{$12 \mathrm{MS} \mathrm{A}$} \\
\hline & Asli & $\begin{array}{c}\text { Trans } \\
\sqrt{ }(x+0,5)\end{array}$ & Asli & $\begin{array}{c}\text { Trans } \\
\sqrt{ }(x+0,5)\end{array}$ & Asli & $\begin{array}{c}\text { Trans } \\
\sqrt{(x+0,5)}\end{array}$ \\
\hline \multicolumn{7}{|c|}{ Dosis Glifosat $(\mathrm{g} / \mathrm{ha})$ : } \\
\hline 1080 & 68,75 & $8,28 \mathrm{a}$ & 81,25 & $9,04 \mathrm{a}$ & 88,75 & $9,44 \mathrm{a}$ \\
\hline 1440 & 67,5 & $8,21 \mathrm{a}$ & 80,00 & $8,95 \mathrm{a}$ & 83,75 & 9,16 a \\
\hline 1800 & 72,5 & $8,50 \mathrm{a}$ & 81,25 & $9,01 \mathrm{a}$ & 87,25 & $9,36 \mathrm{a}$ \\
\hline 2160 & 82,5 & $9,07 \mathrm{a}$ & 92,50 & $9,63 \mathrm{a}$ & 50,00 & $6,40 \mathrm{~b}$ \\
\hline Siang Mekanis & 0,00 & $0,71 \mathrm{~b}$ & 0,00 & $0,71 \mathrm{~b}$ & 0,00 & $0,71 \mathrm{c}$ \\
\hline Kontrol & 0,00 & $0,71 \mathrm{~b}$ & 0,00 & $0,71 \mathrm{~b}$ & 0,00 & $0,71 \mathrm{c}$ \\
\hline $\mathrm{BNT} 5 \%$ & & 1,01 & & 0,74 & & 2,19 \\
\hline
\end{tabular}

Keterangan : Nilai Tengah yang diikuti oleh huruf yang sama tidak berbeda menurut uji BNT pada taraf uji 5\%. 
pada 4, 8 dan 12 MSA, herbisida glifosat dosis 1080$2160 \mathrm{~g} \mathrm{ha}^{-1}$ menekan pertumbuhan gulma daun lebar di lahan kelapa sawit TBM pada 4 dan 8 MSA, gulma rumput ditekan pada $12 \mathrm{MSA}$, dan gulma teki ditekan pada 4 MSA, terdapat perubahan komposisi jenis gulma akibat aplikasi herbisida glifosat yang ditunjukkan oleh jumlah jenis gulma yang berbeda pada setiap perlakuan yang dibandingkan dengan kontrol, serta semua taraf dosis herbisida glifosat yang diuji tidak meracuni tanaman kelapa sawit belum menghasilkan.

\section{DAFTAR PUSTAKA}

Adnan, Hasanuddin, dan Manfarizah. 2012. Aplikasi Beberapa Dosis Herbisida Glifosat Dan Paraquat Pada Sistem Tanpa Olah Tanah (TOT) Serta Pengaruhnya Terhadap Sifat Kimia Tanah, Karakteristik Gulma dan Hasil Kedelai. J. Agrista 16 (3) : 135-145.

Apriadi, W., D. R. J. Sembodo,dan H., Susanto. 2013. Efikasi Herbisida 2,4-D Terhadap Gulma Pada Budidaya Tanaman Padi Sawah (Oryza Sativa L.). J.Agrotek Tropika. 10 (2) : 79-84.

Hermawan, W., W. Djulkarnain, A. Pasaribu, dan Tuharto. 1995. Efikasi beberapa campuran antara herbisida glifosat $18 \%$ dengan herbisida selektif lainnya terhdap pengendalian gulma pada padi sawah tanpa olah tanah. Prosiding Seminar
Nasional V. : Budidaya Pertanian Tanpa Olah Tanah. 8-9 Mei 1995. Bandar Lampung. Hlm 14.

Mawardi, D. 2005. Efikasi herbisida glifosat untuk persiapan budidaya jagung tanpa olah tanah. J.Agrotropika. 10 (2): 79-84.

Sembodo, D. R. J. 2012. Bahan Kuliah Herbisida dan Lingkungan. (Tidak dipublikasikan). Universitas Lampung. Bandar Lampung.

Nurjannah, U. 2003. Pengaruh dosis herbisida glifosat dan 2,4 D terhadap pergeseran gulma dan tanaman kedelai tanpa olah tanah. J. Ilmu-Ilmu Pertanian Indonesia. 5 (1): 27-33.

Satyawibawa, I. dan Y. E. Widyastuti. 1999. Kelapa sawit belum menghasilkan : Usaha budidaya, pemanfaatan hasil, dan aspek pemasaran. Penebar Swadaya. Jakarta. $218 \mathrm{hlm}$.

Sukman, Y., dan Yakup. 1995. Gulma dan Teknik Pengendaliannya. CV Rajawali Press. Jakarta. $157 \mathrm{hlm}$.

Syamsulbahri.1996. Bercocok Tanam Tanaman Perkebunan Tahunan.Gajah Mada Press. Yogyakarta. $177 \mathrm{hlm}$.

Tim Penulis Penebar Swadaya. 1994. Kelapa sawit belum menghasilkan Usaha Budidaya, Pemanfaatan, Hasil, dan Aspek Pemasaran. Penebar Swadaya. Jakarta. 218 hlm. 